\title{
Paideusis
}

\section{The Role of Difficult Art-works in Teaching to be Critical}

\section{Michelle Forrest}

Volume 14, Number 2, 2001

URI: https://id.erudit.org/iderudit/1072797ar

DOI: https://doi.org/10.7202/1072797ar

See table of contents

Publisher(s)

Canadian Philosophy of Education Society

ISSN

0838-4517 (print)

1916-0348 (digital)

Explore this journal

Cite this article

Forrest, M. (2001). The Role of Difficult Art-works in Teaching to be Critical.

Paideusis, 14(2), 39-58. https://doi.org/10.7202/1072797ar

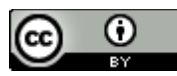

This document is protected by copyright law. Use of the services of Erudit (including reproduction) is subject to its terms and conditions, which can be viewed online.

https://apropos.erudit.org/en/users/policy-on-use/
This article is disseminated and preserved by Érudit.

Érudit is a non-profit inter-university consortium of the Université de Montréal, Université Laval, and the Université du Québec à Montréal. Its mission is to promote and disseminate research.

https://www.erudit.org/en/ 


\section{The Role of Difficult Art-works in Teaching to be Critical}

\section{Michelle Forrest, Mount St. Vincent University}

\section{Abstract}

The difficult art-work is not formally considered an appropriate part of today's arts curriculum, as a glance at authorised classroom resource lists quickly confirms. By excluding from formal compulsory education the conceptual challenges offered by difficult work such as the poetic experiments of the Dadaists or the book-works and textual interventions of contemporary artists, we encourage a closed concept of art and can hardly be surprised at public outcries against avantgarde invention. This paper argues for the inclusion of difficult art-works in the secondary-school arts curriculum. George Steiner's four levels of poetic difficulty are used as a way of demonstrating which difficulties are included in the curriculum and which are peculiar to art-works but rarely studied. Examples of classroom applications are used to illustrate each of Steiner's four levels of difficulty: contingent, modal, tactical and ontological. It is argued that ontological difficulty distinguishes many of the art-works that have evoked public indignation and outrage; they ask blank questions and thereby challenge conventional concepts of art. This ontological difficulty is considered in light of Immanuel Kant's concept of aesthetic/reflective judgement and the discussion is brought full-circle with the question: If engagement with difficult art-work fits Kant's description of how aesthetic judgement postulates " $\mathrm{a}$ universal voice about a liking unmediated by concepts", how can secondary-school arts education neglect the conceptual difficulty of modern works and claim it is teaching art in its unique capacity for teaching to be critical?

\section{Introduction}

Once, while visiting a family friend in Manhattan, as we strolled around the courtyard of Lincoln Centre, I was struck by the irritation she expressed on approaching the reflecting pool and seeing the gigantic Henry Moore sculpture of a reclining figure. "That's not art!" she said indignantly. I was surprised and asked a few questions to find out why it provoked such irritation. She felt that the sculpture did not realistically resemble a reclining woman. The first time I heard the that's not art! response was in muffled tones at London's Tate Gallery as I gazed with other visitors at a row of shoes with roses in them. This occurred many years ago, when my gallery-going had just begun. I took no notice of who created the peculiar 
sculpture of shoes with roses. Two other visitors huffed their indignation. I was puzzled but gave the work no serious thought. I was looking for the highly publicised Salvador Dali show. Now I see the irony in my racing past shoes with roses in search of Dali's melting time-pieces.

Artists in all media challenge our expectations with objects, installations, performances and concepts we may prefer not to consider. ${ }^{1}$ One need only recall examples of controversy over the purchase and exhibition of art-works such as Barnett Newman's "Voice of Fire" and Jana Sterbak's "Vanitas: Flesh Dress for an Albino Anorectic". 2 These works evoked a widespread public response of that's not art! What does this say about arts education? How interested are we in art that challenges systems and sets of formalities? Do difficult works belong within the scope of compulsory education? What concept of art do we encourage students to hold?

One may think that a challenging engagement with difficult art should be left for post-secondary education; that one needs more experience and the effects of maturity. The problem with waiting until people are well into adulthood before exposing them to difficult art-works is that by then their tastes and categories tend to be firmly fixed. The works that challenge publicly held opinions and categories need to be introduced early in one's learning, as are many of life's other difficulties. In today's classrooms devoted to the literary arts there is a lack of exposure to the contemporary artistic inventiveness that challenges the very categories teachers depend on to analyse and interpret the works selected for their curriculum. Though we may touch upon the history of the avant-garde, this tends only to expose students to examples of works that challenged former societies, works we have since interpreted into fixed categories and learned to accept as art. It is a good starting place, to begin with the historical avant-garde, but we need to follow through by including works that continue to challenge concepts of art.

The purpose of this essay is to examine the theoretical and philosophical basis for including difficult works in the school curriculum. I begin from the premise that it is the difficult inventive nature of art-work persisting with no apparent use-value that makes it characteristically different from other processes and products of human endeavour and that these characteristics suggest a foundational role for difficult art in formal compulsory education. Teaching students to be critical is a central curricular aim in democratic societies. ${ }^{3}$ Because difficult art requires one to imagine other contexts and shift frames of reference suggests it may have a significant role to play in teaching to be critical.

George Steiner has considered the concept of difficulty in poetry, 
distinguishing four types. He calls his speculations a working paper; that is, one that is meant to provoke further thought on the subject and, I would add, one that is not meant to be turned into a prescriptive set of categories for teaching art-works. Steiner's insights into the difficulties of poetry offer interesting ways of considering teaching across all arts education. I shall attempt in what follows - a consideration of Steiner's types in light of teaching in the arts - to offer examples that suggest a significant role for difficult art-work in teaching to be critical.

\section{Steiner on 'difficulty'}

Steiner asks: "What do we mean when we say: "this poem, or this passage in this poem is difficult?"'. He wonders how it is that the language-act most charged with the intent of communication "be opaque, resistant to immediacy and comprehension, if this is what we mean by "difficulty'?"4 Steiner points out that on a crucial level this is a question about language itself, a question that admits of no coherent answer without a complete model of the relations between thought and speech and a total epistemology, neither of which we have.

In such a model 'difficulty' would, presumably, be an interference-effect between underlying clarity and obstructed formulation. This, roughly, is the classical and Cartesian reading of opaqueness, a reading whose inference is necessarily negative. But all the relevant terms - 'inside'/'outside', 'intentionality'/'verbalization', and the crucial 'between' with its innocent postulate of a kind of mental space - are notoriously elusive. They activate a metaphor of separation and transfer about which neither logic nor psychology are in any agreement. ${ }^{5}$

Steiner considers his question about poetic difficulty to be narrower. A reader presumes the poet intimates a continuity between her intention and the poetic utterance. By saying that a text is difficult, we mean a number of different things, says Steiner, and he sets out to attempt a typology of some of the principal modes of difficulty as one meets them in poetry.

He begins by distinguishing difficulty in poetry from conceptual difficulty; to find a poem difficult has a different weight or bearing from finding difficult a philosophical argument or a theorem in algebra. Calling algebra a dynamic tautology, "the rigorous unfolding of previously axiomatized definitions," Steiner allows that it is not altogether clear epistemologically what it means to say that one or another step in the process is difficult. He feels, however, that we can agree it is different from poetic difficulty where we may be aiming at something "far less inherent or 'substantive' . . . than concept."

Steiner goes no further in articulating this broad distinction. It is helpful, nonetheless, in suggesting that to experience difficulty in the process of applying 
first principles to a question or problem is difficulty of a different sort from that experienced with poetic language. In both cases one needs the skill of thinking of one thing in terms of another (i.e., one uses analogy and metaphor to make a point in math as well as in a poem). A poem's first principles would be the ordinary denotations of its language and its opening conceit or series of tropes. However, these may shift unexpectedly, in a puzzling way, and may do so differently with each reading and from reader to reader. Though the reader new to poetic language may, in such an instance, charge the poet as incompetent for being puzzling, one accustomed to poetry enjoys the reverberation of meaning, extending possible applications of a metaphor, allusion or other poetic device into the vast reaim of human experience. In poetry and the other arts ambiguity is often an intended effect. As for arriving at a 'complete reading' of a given work, the reader needs to make choices by weighing evidence and discerning a pattern of interpretation that carries through the piece. At this point, there may be a number of encounters with conceptual and poetic difficulty. For example, students may find it useful to understand the concept of the Great Chain of Being before being expected to grasp the effectiveness of Shakespeare's imagery around nature in revolt in King Lear. Not all difficulty in art is that which Steiner terms 'poetic'.

\section{Contingent difficulty}

In teaching the arts, one helps students through various difficulties as they attempt to engage with art-works. The most common order of difficulty is that which Steiner calls contingent: looking up words, phrases, or references which for myriad reasons make a work of art inaccessible. ${ }^{7}$ As Steiner puts it, "[t]hese difficulties arise from the plurality and individuation which characterize world and word." ${ }^{\text {s }}$ Many of the difficulties students have in encountering works of art are due to lack of experience with the elements of the work itself. How is one to engage meaningfully with a medieval icon without knowing something of its context? A viewer accustomed to photo-realism and cinematic special effects may dismiss the images as stiff and 'unrealistic'. To learn that icon painting was and is a complex technical system based upon theological belief may help the viewer put aside her initial dislike long enough to begin to engage with an icon on its own terms and in its own context. Overcoming contingent difficulties is a first step in making a work accessible. We must teach the semantic and background knowledge necessary to allow students to begin to engage with a work of art. 


\section{Modal difficulty}

Another order of difficulty is that which Steiner calls modal. ${ }^{9}$ There are no answers to be looked up; rather, there is a gap between the reader's sensibility and the relevant frame of perception for receiving the work. As Steiner says, an artwork's "idiom and orders of apprehension [may no] longer [be] natural to us". ${ }^{10}$ To illustrate modal difficulty, Steiner refers to Richard Lovelace's lyric poem "La Bella Bona Roba" in which the metaphorical ground depends upon a double entendre on the phrase "good Husbandry in men". The male lover is the Huntsman, the speaker of the poem, who calls upon Love to "strike ... [him] the largest doe." Today this metaphorical conceit, used in all seriousness, would not be considered appropriate within our orders of apprehension. Sensibilities have changed regarding referring to women as objects of a hunt or chase; we no longer accept uncritically the relevant frame of reference for receiving such a metaphor. The clever or amusing metaphor of one age may be offensive or simply meaningless in another.

The modal difficulty of Lovelace's poem marks a change in our metaphorical idioms and, under the right circumstances, it could serve to introduce for discussion the issue of equity and women's rights. The teacher might offer for comparison with "La Bella Bona Roba" a poem such as "I Wiped His Tears Away" by Rita Joe, written from the perspective of a battered wife. ${ }^{11}$ Steiner contends that modal difficulties "challenge the inevitable parochialism of honest empathy." 12 The distinctiveness of individual experience may create situations in which one does not empathise in accordance with the prevailing orders of apprehension. Such disjunctions of sensibility are likely during periods of widespread social change such as that provoked by the women's movement in the twentieth century. Contrasting these two poems in a high-school language arts lesson, a teacher may well evoke retrograde sensibilities regarding the respective positions of males and females in society.

Are the limits of honest empathy an impossible impasse for the teacher? I would suggest that by offering a contrasting sensibility the teacher may help broaden those already represented in his/her classroom. Steiner points out that in claiming empathy with works of the past we confound "the reconstructive acquaintance achieved by virtue of knowledge and archaeology of feeling with authentic apprehension, with penetrative inscape."13 Although we cannot authentically relive the apprehensions of another age, the attempt at reconstructive acquaintance can nonetheless serve to stretch existing sensibilities. William Hare says in reference to fiction that "[it] is valuable not only because it shows the rich variety which attitudes can take, but also because it can make us feel the force of an 
emotion on those who experience it."14 It is through the broadening of experience and expression that we learn to extrapolate from our own experience to that of others. Artistic creations offer worlds we may never experience otherwise. Whenever one attempts the imaginative act of putting oneself in another's place, one has changed frames of perception; the imagined terms of reference are different or beyond one's own sense of ground, balance, viewpoint and position. By helping us feel the force of an emotion on another, art creates the conditions for us to care to make these imaginative leaps. Though, as Steiner says, modal difficulty represents an inaccessible "stance towards human conditions," 15 this does not make it inappropriate for a school curriculum. On the contrary, it can help us recognise the limits of our own sensibilities.

A pressing question is whether we ought to drop a work from the curriculum based upon a change or conflict of sensibilities. I am thinking here of The Merchant of Venice, Huckleberry Finn, and To Kill a Mockingbird, each of which has pitted those fearing censorship against those fearing insensitivity and discrimination. It is often left to individual teachers to decide whether or not to teach works that have stirred controversy. Even if one were able to exclude every work that has already proved contentious, this is no guarantee that controversy will be avoided. Frames of perception and orders of apprehension differ from culture to culture and from person to person, not just from age to age. Try as we may to be sensitive to sensibilities not our own, we may tread roughly without realising we are doing so. By including in the curriculum works with modal difficulty marking changes in sensibility generally deemed mere curiosities today, the teacher has time to calmly lay out principles and provide practice in the exchange of interpretations. This may go some way to a better handling of works that provoke heated clashes across frames of reference. ${ }^{16}$

One has to choose works carefully so that modal difficulties aren't overwhelming and frustrating for students or for oneself. These difficulties require contextualization: giving historical background and helping students come to Elizabethan drama, for example, by way of contrast and comparison with aspects of their own lives, or aspects of other works they have studied. ${ }^{17}$ From our sensory and intellectual perspective, the rhythms of Renaissance verse are beyond the everyday experience of listening to English speakers. ${ }^{18}$ If one learns the tenor of that age well enough to try to imagine how Shakespeare may have sounded to his contemporaries, one may begin to grasp that style as distinct within its period. Encouraging people to attempt these imaginative acts of perspective helps develop a capacity crucial to a society that believes in the notion of collective responsibility: the capacity to 
imagine oneself in another's shoes (assuming he or she has shoes). This capacity to stretch one's parochial view by trying to imagine a place beyond it where there exist other orders of apprehension is part of having an open mind.

It is worth noting that developing a familiarity with the idiom of a literary work requires exposure to it through the ear as well as through the eye. The teacher speaks Shakespeare's iambic pentameter aloud and offers the performances of professional actors on stage and film. Students learn the patterns of rhythm and intonation as they would if immersed in a language group foreign to them; that is, by hearing language as it enervates and instigates human action, not as it might appear in a Petri dish for dissection and analysis. Reading aloud is as necessary when teaching the Africadian idioms of Maxine Tynes' poetry as it is for the complex inverted sentences of Dickens or ironic tone of Jane Austen. ${ }^{19}$ Getting the ear used to an idiom is not something one can 'look up'. It is at the level of modal difficulty that many students stall in learning to appreciate literature and other arts. The famous question "Why do we have to study Shakespeare?" is a common response to the strangeness of Renaissance societal and dramatic conventions as well as to the contingent difficulty of the vocabulary of that age. When these difficulties are not considered, yet hours of reading the text continue, it is little wonder that students question the purpose of the exercise. Two hours in a theatre, preferably watching the action up close, and "[w]e choose to be deceived."20 There is the play of human emotion, motivation, and the conflict of action, which captures interest allowing the receptive attitude necessary for difficulties to develop, evolve, resolve and continue to proliferate. It is in this state of suspended disbelief that we are challenged to open ourselves up to the new and strange.

Steiner goes on to say that our culture seeks to efface the distinction represented by modal difficulty; that it "professes to know less but to feel more than any before it." Though we claim "confident empathy" with every genre and epoch of Western art, we may have to look up even "the most elementary of scriptural, mythological, historical, literary or scientific terms or references". Citing Malraux's point that through modern means of reproducing and manipulating imagery we live in a museum without walls that juxtaposes any manner of image with another, Steiner says " $[w] e$ are ashamed to concede any modal inhibition, to confess ourselves closed to any expressive act however remote from our own time and place. But this ecumenism of receptivity is spurious." He does not believe that we can coerce our sensibility into the relevant frame of reference and that this is witnessed by the fact that whole bodies of literature are receding from our grasp. ${ }^{21}$

It would be easy to dismiss Steiner's concern as an élitist call for a return to 
the Western European canon of great works. It would seem, though, that Steiner's point has special relevance at the dawn of the $21^{\text {st }}$ century. Though computer technology grants us speed and ease of access to the world's data banks, it requires more sifting of wheat from chaff than ever before. Children need critical skills earlier than ever as computer play-stations are marketed on the premise that they offer an 'edge' on future success. As we read of complex criminal acts perpetrated by children and wonder how they accessed the information and materials to build bombs or out-wit a railway communications system, we need to ask how it is that their sensibilities have not kept up with their ingenuity. ${ }^{22}$ Are these isolated cases of asocial behaviour? Are they typical childish pranks with the added lethal element of ease of access to potentially dangerous information and materials? Does Steiner offer a clue to a failure in the education of sensibilities? In our efforts to broaden the scope of the literature we read in schools, do we sacrifice the depth of consideration that nurtures sensibility? I am not suggesting a return to studying exclusively the Western canon either. Does Steiner's point not suggest that, as we choose a culturally diverse selection of literature for schools, we need to consider how each text is to be studied in depth while acknowledging the limits presented by modal difficulties?

\section{Tactical Difficulty}

A third level of difficulty is that which Steiner calls tactical. The artist purposely makes things strange to, as Steiner puts it, "deepen our apprehension by dislocating and goading to new life the supine energies of word and grammar."23 We see this when the writer, informed, constrained yet liberated by the entire idiom within which and in opposition to which she works, employs all of this as her own device for goading new understanding to life. An artist's tactics can span any number of categories from inventing neologisms to breaking ranks completely with the larger form within which she works. In Ulysses, James Joyce uses both of these tactics as well as creating possible modal difficulty by alluding to the Greek epic. Tactical difficulties may not be experienced as such if the audience is unfamiliar with the idiom within and against which an artist employs her tactics. Teachers of the arts may report on tactical moves as they have been identified and interpreted in critical studies and reinterpreted for arts curricula; for example, we teach that Shakespeare breaks the convention of ending each thought and sentence at the end of a line. He forces the reader to carry the intonation pattern of that thought and sentence onto the next line and end it on an up-beat or at some other point where the iambic pentameter does not require a stress. We speculate that he uses this device 
(known as enjambement) tactically in order to create a certain effect. By forcing the emphasis to fall unexpectedly, the audience is caught off guard since a repeating pattern leads one to expect more of the same.

To help students understand the tactics of a work, it may be best to begin with something with few, if any, contingent or modal difficulties for the student. One might use an example of a tactical move made in reaction against an idiom with which they are familiar such as the children's story or the popular song. The teacher might suggest comparing a Shakespearian soliloquy to a rap song. Beginning with the rhythmic characteristics of each, one could draw upon students' knowledge of rap to find examples in which the rap artist makes a tactical move by breaking or extending the form. The teacher would then show the tactical digressions in the example from Shakespeare. The exercise might include as an assignment option a live or recorded performance in the rap idiom of an excerpt from Shakespeare. Though the difficulties of Shakespeare still abound, students catch a glimpse of the intricate levels of its tactical invention through comparison with something familiar.

The above comparison could lead to discussion of the modal difficulty many experience with hip-hop and gangsta rap and its depiction of inner city violence. A teacher may choose to avoid the subject considering it inappropriate for the classroom; however, the music is popular and easily accessible. One might want to ask how it compares to the risks Shakespeare took by depicting on stage the murder of a king. This could lead to a broader discussion of how artists make tactical moves such as using Aesopian language to protect themselves from censorship and even imprisonment under totalitarian regimes. ${ }^{24}$

The visual tools available in a wired classroom can be put to good use in helping students come to terms with tactical difficulty. Literary works that experiment with shifting perspective such as the stream of consciousness in James Joyce and Virginia Woolf still prove difficult to the uninitiated. They could be compared to the multiple perspectives demonstrated in the visual art-work of the Cubists and Constructivists as well as to the collage and photo-montage ubiquitous in contemporary design and advertising. Though by virtue of its fixed lens the camera's perspective is more literally fixed than that of the printed word, one can still use collage, photo-montage and film techniques such as zooming in and out as visual counterparts to shifting perspective in literature. Similarly, the hypertextual linking of screens, images and text boxes on the Internet can be compared with the visual qualities of concrete poetry. Though the tactic of shifting perspective may present students with little if any difficulty when viewed in a rock video, it may require a teacher's intervention when encountered in literature. 


\section{Ontological Difficulty}

What if there are art-works with no answer, no one best interpretation of what a work does, says, is or could become? What if there are difficulties that cannot be answered in the literal sense of one question corresponding to a best answer? Life certainly provides us with questions of this sort, about the unfairness of suffering and privation, about the paradox of having individuality in common. Steiner identifies a fourth class of difficulty called ontological. The poet

confronts us with blank questions about the nature of human speech, about the status of significance, about the necessity and purpose of the construct which we have, with more or less rough and ready consensus, come to perceive as a poem ${ }^{25}$ To illustrate, Steiner uses Paul Celan's "Largo", a poem that, even when the reader works through other types of difficulty, still demonstrates "an action of semantic privacy". He says that Celan goes beyond the tactic of having the reader understand slowly or poise upon alternative interpretations; that "[a]t certain levels, we are not meant to understand at all, and our interpretation, indeed our reading itself, is an intrusion". 26

Steiner traces the history of ontological difficulty in the modern era, citing Rimbaud, Mallarmé and Russian formalism and futurism and the movements stemming from them. To ask why ontological difficulty became a facet of European literature in the late nineteenth and early twentieth centuries is, he says, "to ask an absolutely fundamental question about the crises of idiom and values in the entirety of Western culture". ${ }^{27}$ In ontological difficulty, "the poetics of Mallarmé and Heidegger, of the Orphic and the pre-Socratic, express their sense of the inauthentic situation of man in an environment of eroded speech."28

A work that I have used to interesting effect in my classes in teacher education is Ron Wakkary's 1995 piece "Dictionary of Received Ideas". 29 From a distance the work appears to be a slim volume printed in black typeface on plain white paper. Without closer inspection one could easily miss the singularity of this inconspicuous little book, for that is what it seems to be. Up close, however, one sees that the typeface appears fragmented, as if something went wrong in the printing process but, try as one may, no 'words' are legible other than "R. Wakkary 1995 " on the back cover. One can discern only the patterns of how the fragments cover the pages. Having examined this work and without knowing anything about Wakkary's project, my students have asked, "What kind of book is this?" This has lead to questions about the reading process and what it means to be literate; though they are 'reading' this book, they are not doing so in a conventional way. Wakkary's work presents them with ontological difficulty in that they begin to question the nature of the thing before them, the nature of other things and processes 
to which this object alludes and the nature of their own responses. The question "What does this mean?" is left blank since the work resists comprehensibility. Where the questioning leads from there is so open and arbitrary that one cannot arrive at a definitive interpretation.

The artist's statement about Encyclopedia, the web-based project of which "Dictionary" is a part, helps one understand the intention behind the making of such a peculiar object. Wakkary invented his own typeface, "Alphabet", which he purposely made unrecognisable and used to reprint Gustave Flaubert's "Dictionnaire des Idées Reçues", making the work

unintelligible to the casual reader. The rudiments of meaning are misplaced here.

The reader must learn at the morphemic level what each character represents before he or she could understand Flaubert's parody. ${ }^{30}$

Given Wakkary's intention to disrupt meaning and the allusion to Flaubert in the title the piece begins to yield to interpretation. Wakkary furthers Flaubert's parody of society's acceptance of an authoritative body of knowledge. His work plays with the delivery system of that knowledge by interrupting the expected relationship between the morphemic and semantic levels of written language. For my students, asked to respond to "Dictionary" at (type)face value, the difficulty was ontological. Knowing more about Wakkary's project, one is able to link an interpretation to the artist's intention and the difficulty begins to seem more tactical. It appears not to have been Wakkary's intention to confound us completely, although, to paraphrase Steiner, "[w]e do not 'read' the [work] in the traditional framework of the author's auctoritas and of an agreed sense, however gradually and gropingly arrived at."3I

Is there a role in secondary arts education for ontological difficulty in the full sense as Steiner describes it? It is up to the teacher to decide how ready her students may be for the various levels of difficulty. In certain instances works that defy interpretation may confuse students as they learn the skills of literary and art criticism. On the other hand, to leave out such works is to omit an important aspect of the arts in the twentieth century, an aspect that, as Steiner suggests, arose in response to "the semi-literacies characteristic of a technocratic and mass-consumer society". ${ }^{32}$ We consider it valuable to include the study of popular media. Why not include examples of some of the more esoteric responses artists have made to our "environment of eroded speech"? At the high-school level it would not be appropriate to weigh down the curriculum with works that provoke what Steiner refers to as "the most urgent questions in the whole of aesthetics and of the modern attempts at a philosophy of meaning". ${ }^{33}$ We can, however, give students some introduction to these questions.

It is not the purpose of this essay to delineate further aesthetic distinctions

Paideusis 14:2, 2001 
among Steiner's types of poetic difficulty. However, I would suggest that by choreographing students' introduction to a work as I did with Wakkary's piece, tactical difficulty can evoke 'blank questions' characteristic of ontological difficulty. Works that challenged interpretation in the past continue to do so today for those unacquainted with these challenges. The following example, from a Grade 12 literature class, is the experience that first sparked my interest in the pedagogical value of difficult art-work. ${ }^{34}$

Students are presented with Chekhov's "An Enigmatic Nature", a two-page account of a brief exchange between strangers, a woman and man, sharing a train compartment. The teacher reads the story aloud, explaining the one or two words that might present contingent difficulty. One student says that the story is stupid. Others agree. When the teacher asks why, someone says: "Because nothing happens." Everyone agrees and wants to know what the teacher thinks. She defines the word 'enigma', expecting that this may help. When no one makes the leap or dares a guess, she goes on to explain the slice-of-life genre of short story, but the students still want to know what the story is about. The teacher compounds the enigma by not providing an interpretation. When she asks what it means to say that something happens, some students' impatience turns to indignation. They feel they are being manipulated by the teacher who, it seems, is holding back the right answer to make them think.

More mature readers with a broader knowledge of twentieth century literary genres would not find the slice-of-life story difficult. However, it presents the students in this scenario with unanswerable questions given what they have learned to date about the short story form. How can this story be called a 'short story' when it doesn't fit the system of elements they have studied, a system based primarily upon plot and conflict? They have been lead to question the nature of the construct they have come to perceive as a short story. This was the challenge realism and naturalism posed to the formulaic structure of the short story at the turn of the $20^{\text {th }}$ century. Once the teacher helps the students reinterpret the concepts of plot and conflict and goes into more detail about the slice-of-life genre, the difficulty can be resolved as tactical. To the uninitiated reader, however, the enigmatic nature of the unfamiliar genre can shake the interpretive conventions used in secondary literature classes. It can seem to defy understanding and provoke the blank questions raised by ontological difficulty.

In the process of teaching students to deal with contingent, modal and tactical difficulties we are engaged in the vital work of teaching them new categories for making finer distinctions among the objects of the curriculum. This 
is the crux of compulsory formal education. We include works that stretch students beyond their existing categories, works that demonstrate the inventive twists and turns artists discover in their use of the taken-for-granted. In order to open ourselves to the possibility of invention and discovery in our classrooms we as teachers also need to expose ourselves to new difficulties. There are works that challenge our concept of that which they claim to be: art. This is what art continues to do in its characteristic critical project; it challenges the status of its own significance. According to the Kantian notion of aesthetic reflective judgement, we are not engaged in art unless are categories are so challenged.

\section{Aesthetic reflective judgement}

This argument that even ontological difficulty ought to be part of compulsory arts education is supported by the famous hobby-horse of aesthetics: Immanuel Kant's concept of aesthetic reflective judgement. He distinguishes between determinative and reflective judgement. "Judgment in general is the ability to think the particular as contained under the universal." ${ }^{35}$ If the universal is given - i.e., if we start with a rule or law or principle or definition - then, says Kant, judgement is determinative. We determine over which particular or particulars the universal legislates. For example, under the rules of harmonic progression we judge whether a particular progression of musical chords complies with or breaks the given rules. Similarly, with the short story, we learn what elements are common to things in this category and determine how a particular example fits or adapts or defies the categories as conventionalized through use by artists, critics, scholars and teachers. Although in these examples we are deciding something connected with art, our judging is not of an aesthetic kind. It is judging according to pre-determined limits; it is a matter of fitting the particular to a set of rules, definitions, elements, etc. When a progression of sound or phrasal combinations steps beyond the rules recognized as common to the existing body of work in the form it claims to belong to, we are challenged to stop and reflect. "[ח]f", as Kant says, "only the particular is given and judgment has to find the universal for it, then this power is ... reflective." ${ }^{36}$ We reflect upon the rogue particular to find it a universal whose legislation provides us with the means to understand it; that is, find it a slot within the range of categories by which we organize our understanding of the world. Without this organizing capacity - this conceiving of categories - we would be faced with a new and mystifying world at every turn. I cannot offer an example of a particular with no universal since our judging facility is such that it seeks immediately to name that which is new. To name is to categorize. Our judging 
faculties seek to determine categories in the way a vacuum seeks to fill itself.

This drive to supply universals is a facet of the survival instinct; the need for sustenance drives our capacity to recognize its markers. The infant learns to extrapolate from the source of care to those sounds, smells, textures which always accompany it. One might say that the infant is determining those patterns that need to be recognized in order to most effectively and accurately express his or her desires. Most of the particular cases we encounter give us little room for reflective judgement in the Kantian sense; that is, in being stymied regarding a category for them. There are common types of perceptual difficulty that momentarily defy categorization. For example, encountering a noise or shape as one comes out of a sleep, one may misconstrue it for a split second. This happens to me on occasion if I am waking up away from home. In my half-sleep, I expect to see what I am used to seeing on waking and through closed lids I orient myself to the light source as I would at home. To then open my eyes and find that things do not fit my prefiguring of the space, that the light source is, say, on the opposite side of the room, gives me a sudden case of vertigo. In that split second before all my senses are alert, I have misread my position in that space. In such a case as this, there is no time for reflection. Things right themselves immediately and the disorientation slips away as quickly as a dream scenario so vivid before the moment of waking.

This is an ordinary instance when universals - the 'rules' or 'bearings' by which I orient myself in my usual space at waking - have been applied to a misreading of the particulars needing judgement. It is more a matter of things being out of synch, a kind of sensory glitch. The example foregrounds two things: the disorientation when the particular doesn't fit the universal to which one assumes it ought to belong and the urgency to find a fit, ${ }^{37}$ to get the world back into one's notion of synch. When art challenges conventional notions of what art is or what it ought to do and when it also garners financial returns for its makers, people become indignant and even outraged, particularly when public funds are spent on it. When there is public reaction against a difficult or controversial work, be it a nonrepresentational painting or a novel characterizing politically sensitive situations, it is often too late to open people's minds to the artistic project in question; the work has already been sensationalized through scant and sometimes simplistic descriptions in the news media. The that's not art! response signals closed categories.

As we work to resolve difficulties in our classrooms, our judgements and those we encourage in our students are usually determinative: we give to judgement a definition, principle, or rule, and try to fit a set of particulars into it. Kant says 
that reflective judgement postulates "a universal voice about a liking unmediated by concepts" and that this voice is only an idea to which we refer our judgements. When we automatically dismiss difficult works as insignificant, we ignore this reflective voice, avoiding what Steiner calls blank questions. Difficulty in art, particularly ontological difficulty, allows this voice to sound. It is up to the teacher to provide a safe space for reflecting upon that for which we have no ready categories, that which may challenge categorisation itself.

\section{Conclusion}

I have said that as teachers, we too must be open to difficulty in art and not assume we are ever beyond it or so experienced as not to be challenged further. This is the artist's challenge: to provoke reflection not only in the neophyte but also in the veteran reader of inventive formal arrangements. In the writing of this paper something in the order of a poetic difficulty presented itself to me. I was using a library copy of Steiner's essay "On Difficulty". When I stopped reading and flipped through the book looking for something to mark my place, I found a curious slip of paper the size of a conventional bookmark. On it were the words: "THEY ARE WATCHING, YOU JUST AREN'T DOING ANYTHING IMPORTANT" emanating from a stick figure whose left eye was a large empty circle. The piece was signed: SP. It was a photocopy and there were lines on either edge of the slip suggesting it had been cut from a larger sheet printed with many of these images.

What kind of thing is this? The piece of paper and my response depended entirely upon chance. Not only is it unlikely that every reader would notice it, but also its audience depends upon the popularity and availability of this actual volume and its currency in the works of its kind. And what about the other copies? Where are they? Was this slip placed in this particular volume by chance or on purpose? And what about the context in which I found it? What an interesting coincidence that in writing about the importance of poetic difficulty, I be confronted with just such a puzzle.

This slip of paper represents a formal operation of a kind different from that which we find hanging in galleries and other contexts where it is clear to the audience: This is a work of art. This work, whatever else it may be, is an intervention in normal expected process. Unexpectedness is also a quality of things other than art-works; for example, finding smudges from someone's sticky fingers, although even that could be expected and even cherished in a child's book. Finding smudges is, however, a normal process. Whatever kind of work this piece of paper represents in the mind of its author, it raises blank questions for me about who they 
are, about the aesthetics and value of scholarly work, about my engagement with books as traditionally defined, and about the record that is kept on the trail of my library borrowings.

Maxine Greene tells us that "[t]eachers, like their students, have to learn to love the questions, as they come to realize that there can be no final agreements or answers, no final commensurability." 38 Is this a realization we must leave for socalled 'higher' education? If we wait that long, what are the chances, in the face of entrenched indignation and the current lack of belief in education as an end in itself, that this light will ever dawn? Greene talks about tendencies which are antithetical to education for freedom because

they impose a fallacious completeness on what is perceived. Instead of reaching out, along with others, toward open possibilities in experience, individuals in all groups accept existing structures as given. They may try to make use of them or escape them or move around them or make a mockery of them; but they feel themselves in some way doomed to see them as objective "realities," impervious to transformation, hopelessly there. ${ }^{39}$

It is often argued that the arts are valuable because they help us recognize and resist existing structures by telling us inspiring stories about such resistance. Such narratives can be found outside artistic forms: in the news, in historical accounts and in the stories we tell one another. The form of resistance artistic engagement offers as model is the struggle of aesthetic reflective judgement to cope with new and difficult openings. As Jeanette Winterson puts it so well: "Art objects. The nouns become a collective force not a collector's item. Art objects." ${ }^{90}$ It is because it objects with its many difficulties that art is valuable. It is because someone had the audacity to put a symbol of fragility and beauty inside a functional object - yes, those shoes and roses - that I am left still wondering.

\section{Notes}

1. This is not to say that all artists intend to pose challenges to their audiences or that every artistic encounter by definition requires such a challenge.

2. "Voice of Fire" is a painted canvas approximately 18 feet high by 8 feet wide consisting of three vertical bands of colour. The difficulty of this art-work was compounded when in 1990 it was purchased by the National Gallery of Canada for \$1.8 million (See Voices of Fire: Art, Rage, Power, and the State, Bruce Barber, Serge Giubaut, John O'Brian, eds., University of Toronto Press, 1996). Sterbak's "Vanitas: Flesh Dress for an Albino Anorectic" is sewn together from 50 pounds of flank steak. The dress cures over a period of weeks from fresh meat to a dry skin, graphically demonstrating the transitory nature of our physical existence. See Brown University News at <http://www.hunger.brown.edu/ Administration/News_Bureau/1997-98/97-007.html>. 
3. In my own province the Department of Education states in The Goals for Public Education, "Public School Programs 2000-2001": "Our vision of an educated person is that of a competent, confident learner able to think critically and participate fully in a democratic society and in a lifetime of meaningful work." Six areas of learning are identified as essential for graduation: aesthetic expression, citizenship, communication, personal development, problem-solving and technological competence. Though problem-solving is the obvious area in which critical thinking takes place, it is interesting to note that in the descriptions of the other five areas there is also mention of elements of critical thinking. (See Government of Nova Scotia, <ftp://ttp.ednet.ns.ca/pub/educ/psp/psp-a.pdf>.)

If one were to accept the definition of critical thinking offered by Michael Scriven and Richard Paul for the National Council for Excellence in Critical Thinking, one might conclude that critical thinking is the omnibus category for the requisite skills and habits of all learning. They define critical thinking as "the intellectually disciplined process of actively and skillfully conceptualizing, applying, analyzing, synthesizing, and/or evaluating information gathered from, or generated by, observation, experience, reflection, reasoning, or communication, as a guide to belief and action." Scriven and Paul contrast their summary of what critical thinking comprises with a mechanistic version that sees it as "the mere acquisition and retention of information alone, . . . the mere possession of a set of skills, ... and the mere use of those skills ("as an exercise") without acceptance of their results." By contrast their concept has two components: "a set of skills to process and generate information and beliefs, and the habit, based on intellectual commitment, of using those skills to guide behavior." (See The Critical Thinking Consortium at <http://www. criticalthinking.org/University/univclass/Defining.html>.)

Throughout the development of the body of literature on critical thinking two debates have been prominent: one concerning the generalisability of critical thinking skills (i.e., does thinking competence in one discipline or field of action necessarily transfer successfully into another), and the other stemming from the critique of rationalism (does a critical thinker care about using her thinking skills with compassion?). (For two notable views from the generalisability debate see John McPeck's Critical Thinking and Education, Oxford: Martin Robertson, 1981 and Robert H. Ennis's "Critical Thinking and Subject Specificity", Educational Researcher April 1989. For an excellent overview of the major challenges to critical thinking as an educational goal see John Portelli's "The Challenge of Teaching for Critical Thinking", Philosophy of Education. Introductory Readings, $2^{\text {nd }}$ ed., Calgary: Detselig, 1996.)

4. George Steiner, On Difficulty and Other Essays, Oxford: Oxford University Press, 1978, 18.

5. Ibid. Steiner's pairs of opposites and his "metaphor of separation and transfer" remind one of Derrida's claim that language is a system of differences and distances. His postal metaphor, a central point made about Husserl's Rückfrage, is the animating trope of $L a$ Carte Postale and a recurring theme of his critique of the metaphysics of presence. Derrida describes Husserl's Rückfrage, translated as question en retour, thus: "Like its German 
synonym, return inquiry ... is marked by the postal and epistolary reference or resonance of a communication from a distance. From a received and already readable document, the possibility it offered me of asking again, and in return, about the primordial and final intention of what has been given me by tradition. The latter, which is only mediacy itself and openness to a telecommunication in general, is then, as Husserl says, 'open . . . to continued inquiry'." [See Edmund Husserl's "Origin of Geometry". An Introduction, John P. Leavey, Jr., trans., York Beach, Maine : Nicolas-Hays, 178, 50 and Jacques Derrida's $L a$ Carte Postale: De Socrate à Freud et au-delà. Collection la Philosophie en effet. Paris: Flammarion, 1980. For a study of the pedagogical implications of Derrida's Writing (sic) see Gregory Ulmer, Applied Grammatology. Post(e)-Pedagogy from Jacques Derrida to Joseph Beuys, Baltimore and London: John Hopkins University Press, 1985 and my 'no ordinary chaos' Heuretics for Media Work in Education, unpublished doctoral thesis, Dalhousie University, 1997.]

7. Steiner, 18-19.

8. Steiner refers to the types variously as 'modes', 'orders', 'species', 'types' and 'classes'.

9. Steiner, 33.

10. Ibid. Steiner notes that the term is used by C.S. Lewis (29).

11. Rita Joe, "I Wiped His Tears Away", Kelusultiek. Original Women's Voices of Atlantic Canada, Halifax: Institute for the Study of Women, Mount Saint Vincent University, 1994, 63.

12. Steiner, 40.

13. Steiner, 32.

14. William Hare, What Makes a Good Teacher, London, Ont.: The Althouse Press, 1993, 110.

15. Steiner, 28.

16. Steiner suggests that there may be another "circuit of reference" in "La Bella Bona Roba": words such as 'Incardine' and 'incorporate' allude to the theological mystery of transubstantiation. This level of reference, dangerous in its day, was veiled by the then benign sexual prescription of this Cavalier lyric.

17. An example of something that attempts to mitigate the contingent and modal difficulties of Shakespeare is Tales from Shakespeare (1807) by Charles and Mary Lamb (New York: Garden City, 1955), a work whose vocabulary and usage present difficulty for today's young readers.

18. This is not to say that Elizabethans spoke in verse, but that many of the contingent difficulties of vocabulary and syntax we experience with Shakespeare today were not a problem for people of his time. Many of his conceits were commonly understood images and metaphors from well-known legend, myth and religious doctrine.

19. The term 'Africadian' was coined by Nova Scotian writer George Elliot Clarke to refer to the indigenous black communities of Nova Scotia and New Brunswick, i.e., L'Acadie. 20. Samuel Taylor Coleridge, "Stage Illusion", lecture notes of 1817 in English Romantic Writers, David Perkins, ed., New York: Harcourt, Brace \& World, Inc., 1967, 498-49.9. 
21. Steiner, 32-33. See also André Malraux's Museum Without Walls (1965), Stuart Gilbert and Francis Price, trans., London: Secker \& Warburg, 1967.

22. I refer to the shootings at Columbine High School, Littleton, Colorado, 20 April, 1999 and the derailment of a VIA Rail passenger train at Stewiacke, Nova Scotia, 12 April, 2001. For the U.S. Surgeon General's Report on Youth Violence (2001) see <http://www. surgeongeneral.gov/library/youthviolence/toc.html $>$.

23. Steiner, 40. In saying that the artist "makes things strange" I allude to the essay "Art as Device" (Iskusstvo kak priem) by Viktor Shklovsky, the Russian Formalist, in which he made his major statements concerning ostranenie, translated as both 'defamiliarisation' and 'making strange'. "The purpose of art" said Shklovsky, "is to impart the sensations of things as they are perceived and not as they are known." See Russian Formalist Criticism: Four Essays, Lee T. Lemon and Marion J. Reis, trans., Lincoln: University of Nebraska Press, 1965, 12.

24. For an analysis of gangsta rap and hip hop music see Michael E. Dyson's Between God \& Gangsta Rap: Bearing Witness to Black Culture, Oxford University Press, 1997, and for a discussion of Aesopian language as used during the Soviet era, see Kevin Moss's "Bulgakov's Master and Margarita: Masking the Supernatural and the Secret Police," Russian Language Journal, Vol. 38, Nos. 129-30 (1984), 115-131.

25. Steiner, 41.

26. Steiner, 45 .

27. Steiner, 41.

28. Steiner, 44.

29. I purchased a copy of the work included in the exhibition Text as Visual Object, St. Mary's University Art Gallery, Halifax, Nova Scotia, Nov. $19^{\text {th }}, 1996$.

30. For an exhibition statement on Encyclopaedia see Stadium, an independent web site for artists' projects located at www.stadiumweb.com. Ron Wakkary is the director and cofounder of Stadium, hosted and promoted by Dia Center for the Arts, New York, N.Y., www.diacenter.org.

31. Steiner, 46.

32. Steiner, 42.

33. Steiner, 47.

34. I attempted to shake up the categories laid down by years of memorising definitions and applying them to literary examples in which the 'fit' was not difficult. I designed a unit that seemed to defy the 'elements' of the short story as traditionally taught in secondary schools. I included stories by Maugham, Mansfield, Anderson and Woolf. Chekhov's "Enigmatic Nature" became the theme for the unit.

35. Immanuel Kant, Critique of Judgment (1790), Werner S. Pluhar, trans., Indianapolis: Hackett, 1987, 18.

36. Kant, 19.

37. Nelson Goodman, Ways of Worldmaking, Indianapolis and Cambridge: Hackett, 1978, p. 21. Goodman contends we represent the world by continually trying to find a fit between 
our experience of it and our representations.

38. Maxine Greene, The Dialectic of Freedom, New York: Teacher's College Press, 1988, 134.

39. Greene, 22.

40. Jeanette Winterson, Art Objects. Essays on Ecstasy and Effrontery (1995), Toronto: Vintage, 1996, 19.

\section{Acknowledgement}

I would like to thank the Paideusis reviewers for their meticulous reading of this text and for asking such difficult questions.

\section{Author}

Michelle Forrest teaches courses in philosophy of education, literacy, the arts and popular culture. Her doctoral thesis both explored and demonstrated the nature of the 'open' artwork. She is part of the scholar-artist collective, $(1+1+1)$, which investigates collaborative process and the inventive and democratizing role of chance operations.

michelle.forrest@msvu.ca 